\title{
Research Protocol
}

\section{Coronavirus Disease-2019, Diabetes and Dialysis in Southern Italy: The Second Wave Follow-up}

\section{Felice Strollo, MD, PhD'; Ersilia Satta, MD²; Carmine Romano, MD²; Carmelo Alfarone, MD²; Teresa Della Corte, BSc ${ }^{2,3 *}$; Giuseppina Guarino, MD, PhD ${ }^{3}$; Maria Pasquarella, MD²; Sandro Gentile, MD, PhD ${ }^{2,3}$}

'IRCCS San Raffaele Pisana, Rome, Italy

${ }^{2}$ Nefrocenter Research Network and Nyx Start-up, Naples, Italy

${ }^{3}$ Campania University "Luigi Vanvitelli" and Nefrocenter Research Network and Nyx Start-up, Naples, Italy

\section{*Corresponding author}

Teresa Della Corte, BSc

Nutritionist, , Nefrocenter Research Network and Nyx Start-up, Naples, Italy; E-mail: tere.dellacorte@gmail.com

\section{Article information}

Received: December 8 ${ }^{\text {th }}$, 2020; Revised: December 16 $6^{\text {th }}$, 2020; Accepted: December 17 $7^{\text {th }}$ 2020; Published: Deceember $22^{\text {nd }}, 2020$

\section{Cite this article}

Strollo F, Satta E, Romano C, et al. Coronavirus disease-2019, diabetes and dialysis in southern Italy: The second wave follow-up. Diabetes Res Open J. 2020; 6(2): 37-46. doi: 10.17I40/DROJ-6-148

\section{ABSTRACT}

\section{Background}

After the official coronavirus (severe acute respiratory syndrome coronavirus-2 (SARS-CoV-2)) pandemic declaration by the World Health Organization (WHO), Italy had the second-largest number of confirmed cases, after China. The Italian government introduced progressive infection-mitigation measurements, thus dramatically reducing social interactions and preventing virus spread. During the summer, infection containment measures progressively loosened until, due to an unjustified interpretation of some permissions and the excessive utilization of public transportation at school reopening, the contagion rate progressively increased until causing a severe challenge for our National Health Service (NHS) again.

Aim

To assess the efficiency of our previously described protocol in 18 Campania region-located Nefrocenter Consortium dialysis centers (DCs) as further adapted to new knowledge under the new ubiquitous contagion conditions and to identify SARS-CoV-2-infection mortality rate and risk factors.

\section{Methods}

381 HCP members underwent regular monitoring on April 1 and November 13, 2020. Dialysis patients did so too during that period according to the expected shifting prevalence over time (mean \pm SD:853 \pm 30 per month; range 825 to 873 ) vs (11.8\% in April, and $14.8 \%$ in November $v$ s. a pre-coronavirus disease-2019 (COVID-19) $12.0 \%$ rate in January).

Results

More patients got infected in November (10.19\%) than in April (0,24\%), and 22 patients of the 89 from the SARS-CoV-2 November positive subjects required hospitalization for moderate-severe symptoms $(24.72 \%)$, with death unavoidably coming in 19 ( $86.36 \%$ of hospitalized and $21.35 \%$ of infected patients) compared to the only one recorded in April ( $0.12 \%)$. The pandemic's two periods showed a strong association between mortality rate and often co-existing comorbidities, primarily represented by arterial hypertension, type 2 diabetes mellitus (T2DM), and chronic kidney disease (CKD).

\section{Conclusion}

The previously efficient contagion containment measures adopted by our DCs were not enough in November to fight the global infection risk pending on the whole Italian social community around. The author, discuss possible reasons and put forward further suggestions for the best handling of any future infection waves.

Keywords

COVID-19; Dialysis; Diabetes; Prevention; Contagion; COVID second round.

\section{PREMISE}

$\mathrm{W}$ spreading worldwide of severe acute respiratory syndrome coronavirus 2 (SARS-CoV-2). ${ }^{2}$ In March 2020, Italy got the second-largest number of confirmed cases, after China. The Italian government outbreak a pandemic on March 11, 2020 ${ }^{1}$ due to a rapidly

(c) Copyright 2020 by Della Corte T. This is an open-access article distributed under Creative Commons Attribution 4.0 International License (CC BY 4.0), which allows to copy, redistribute, remix, transform, and reproduce in any medium or format, even commercially, provided the original work is properly cited. 
introduced progressive infection-mitigation measurements on March 9 and March 11, 2020, to dramatically reduce social interactions and prevent virus spread. ${ }^{3,4}$ Contagion cases dramatically decreased during the following months. This led to progressively looser infection containment measures allowing free tourism and commerce-related exchanges among regions and mask-based socialization within coffee-bars, restaurants, pubs, and other gathering places while still adopting strict hand hygiene and proper
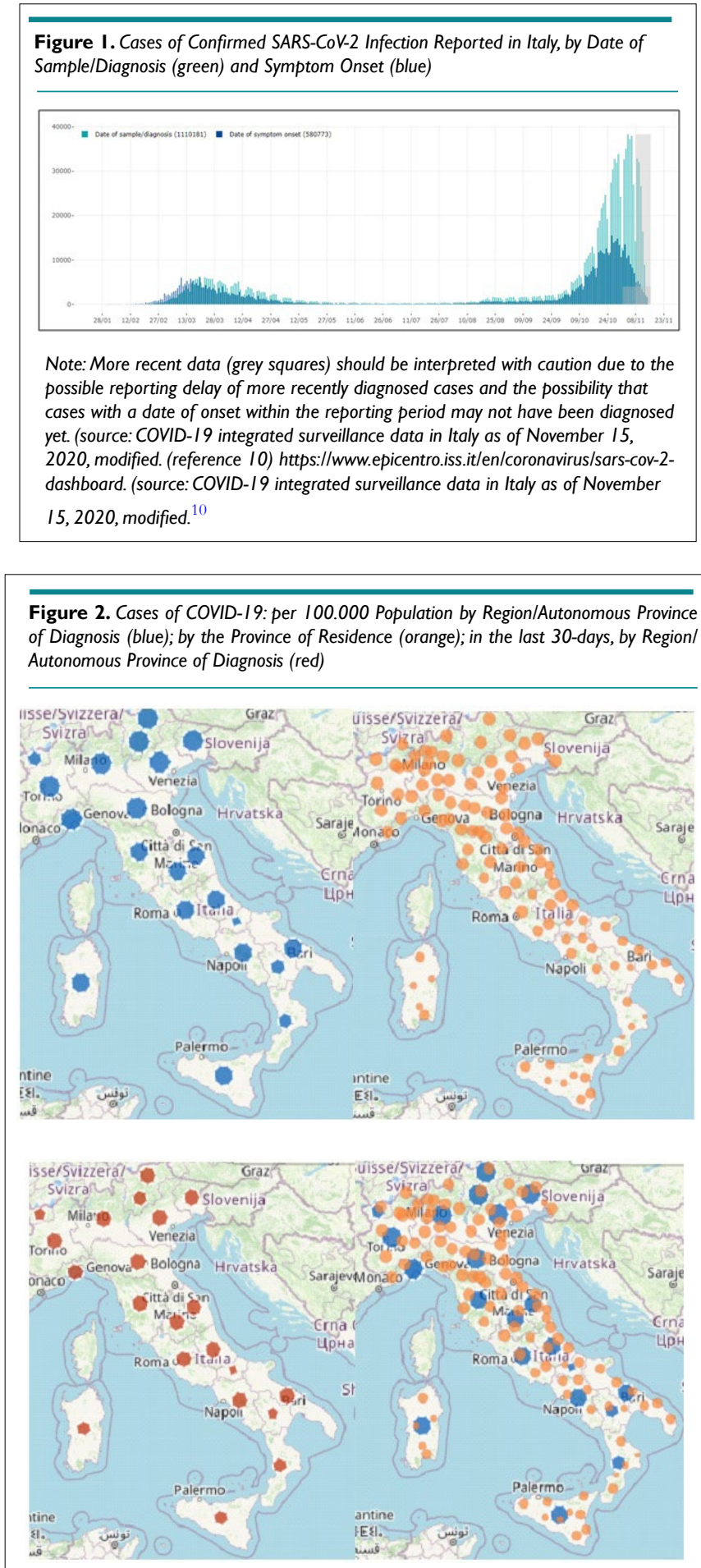

Source: COVID-19 integrated surveillance data in Italy as of 15 November, 2020, modified. $^{10}$ inter-personal distancing. Unfortunately, as people interpreted that as fully regained freedom and, after a while, school reopening caused unrestricted use of public transportation, contagion rate progressively increased from August up to the present situation, which represents a severe challenge for our National Health Service (NHS) (Figure 1). However, the two periods of COVID-19 pandemic markedly differed from each other: between February and April, most cases occurred in Northern Italy, being the Central and Southern parts largely preserved while all regions appeared to be interchangeably under attack during the second infection wave (Figure 2). 5,6

In April, the difference between the two national areas seemed to depend on unevenly distributed weather and pollution conditions. ${ }^{6,7}$ The latter were mostly due to pressing industrial activities involving the extensive use of public transportation by many workers undergoing long-term confinement within closed environments to provide our country with scheduled production rates. ${ }^{8}$ As reported by some authors, including ourselves, a few other factors might add to different contagion rates initially, including uneven tracking ability and implemented strategies against the viral spread. ${ }^{7,9}$

\section{Frail Population: Patients on Dialysis with and without Diabetes}

During the first period of the SARS-CoV-2 pandemic, we analyzed contagion rate in both a large cohort of patients and health care professionals, including auxiliary workers (HCWs) from 18 Southern Italy Nefrocenter Consortium dialysis centers (DCs). Our results ${ }^{10,11}$ were in agreement with those reported by the Italian National Institute of Health (NIH).${ }^{12}$ Our interest in people on dialysis relied on the high prevalence of comorbidities expected to shorten life expectancy per se observed in such population, including type 2 diabetes mellitus (T2DM), ${ }^{13,14}$ arterial hypertension (AH) and cardiovascular disease (CVD) and on the high contagion risk entailed by repeated attendance of health care facilities.

There is some discrepancy between contagion prevalence $(13.9 \%)$ and mortality rate $(16.2 \%)$ in Chinese series ${ }^{15}$ and those reported in Italy $(2.5 \%$, except for Lombardy, where an average $7 \%$ death prevalence was reported, with a top $14 \%$ rate in Cremona).${ }^{16}$ On adopting a prevention protocol in agreement with the Italian Nephrology Society (INS) recommendations ${ }^{17,18}$ and with Chinese experience, ${ }^{19}$ Nefrocenter Consortium DCs reported as low as $0.24 \%$ a prevalence and $0.12 \%$ a mortality rate $(2$ and 1 out of 825 patients, respectively). ${ }^{11}$ None got infected among the 351 health care personnel (HCP) members from the 18 DCs until April 23 , 2020. The above observations support the high effectiveness of chosen contagion containment measures, especially considering repeated, long-standing exposure to promiscuity conditions of frail, immune-compromised individuals. ${ }^{20-25}$ However, the lower inflammatory cytokine levels reported in dialyzed patients might have also contributed to the relatively mild clinical course of COVID-19 observed in that period. ${ }^{26}$

Unfortunately, the second wave of COVID-19 pandemic is now quite different from the first one, by hitting all Italian regions almost equally with a high contagion rate both at home 
and in varying health care settings. ${ }^{27,28}$ Due to the consequent large number of apparently healthy carriers, the above protocol might prove less efficient than before.

\section{Aim of Prevention Protocol and Infected Patient Management}

Our study aimed to evaluate the efficiency of our previously described protocol ${ }^{11}$ under the new ubiquitous contagion conditions. The secondary outcomes were (i) SARS-CoV-2-infection mortality rate and risk factors; (ii) identifying further actions to be taken to provide SARS-CoV-2 positive dialyzed patients and HCP with undeferrable treatment in the 18 Campania region-located private Nefrocenter Consortium DCs contracted to the Italian NHS.

\section{PROTOCOL}

As defined according to INS recommendations ${ }^{28-30}$ and Chinese experience, ${ }^{19,31}$ the protocol has been running since the epidemic outbreak in Lombardy, i.e., February 20, 2020, to limit the spread of contagion among both patients and HCP directly or indirectly involved in dialysis-related activities. We already described protocol details,${ }^{11}$ to which we added recommendations on the management of COVID-19 patients under the latest documents released by the Italian Ministry of Health $(\mathrm{MoH})$, the ISS, and the WHO. ${ }^{32-34}$ Figure 3 provides a detailed protocol flowchart. As for the HCP, the latter was superimposable to the previous one oriented to people on dialysis, ${ }^{11}$ except for eventually occurring COVID-19 dedicated DCs.

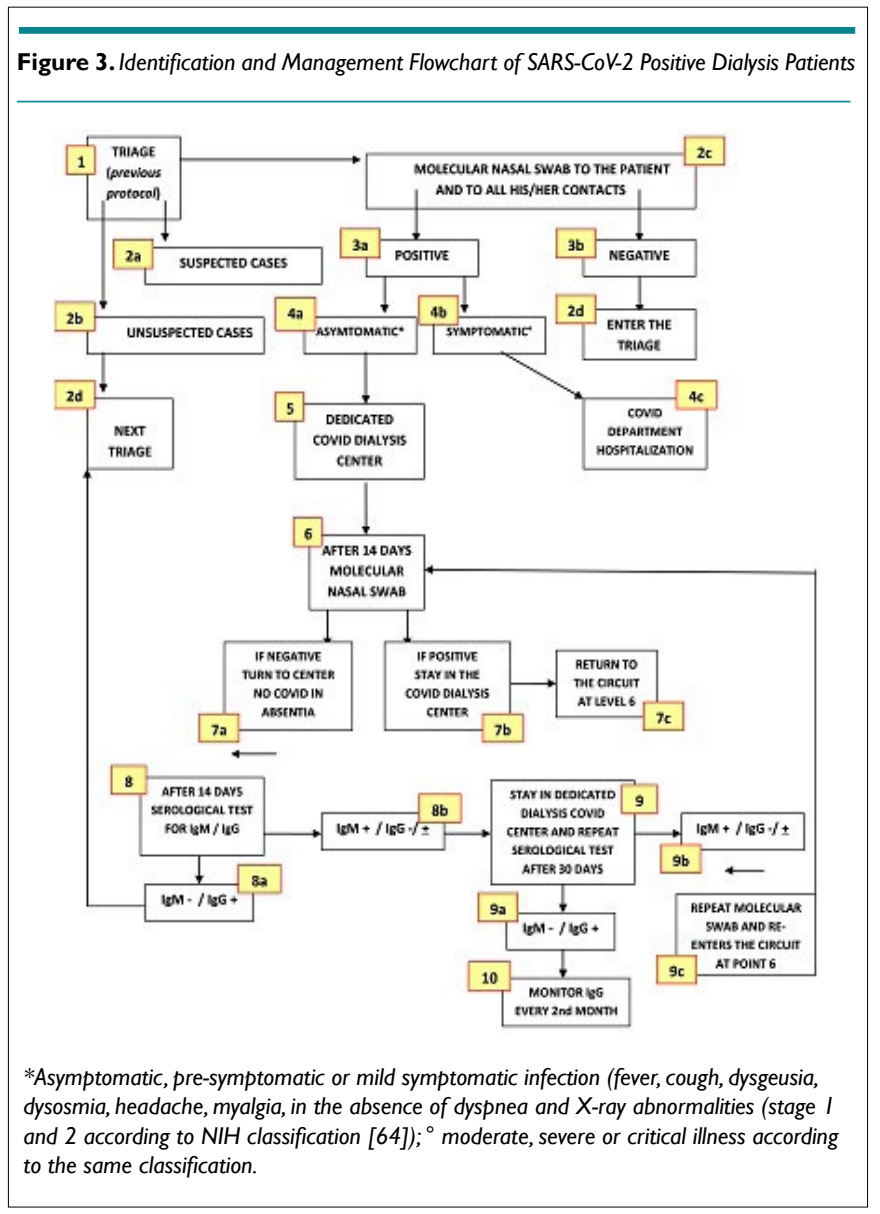

\section{METHODS}

On April 23 and November 13, 2020, 381 HCP members underwent regular monitoring (Table 1), while dialysis patients ranged 825 to 873 according to the expected shifting prevalence over time (mean \pm SD: $853 \pm 30$ per month throughout the 6.5-months). Overall Italian all-cause mortality rate was $11.8 \%$ in April and $14.8 \%$ in November vs. a.

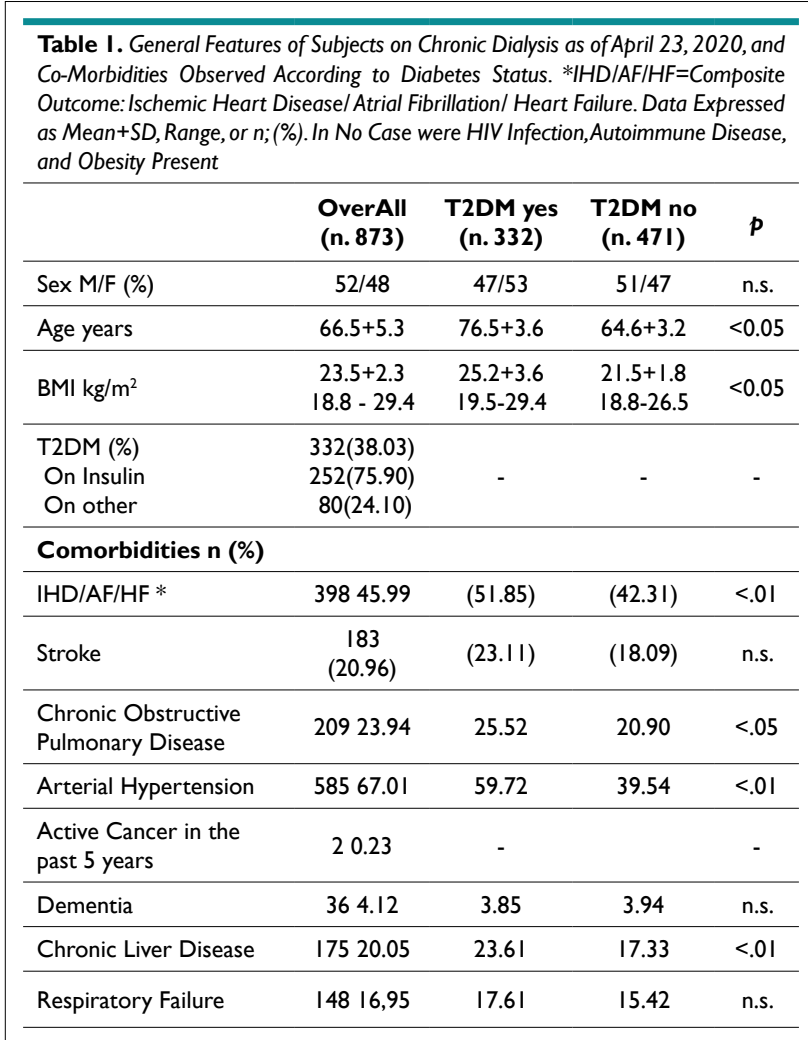

Following Italian $\mathrm{MoH}$ recommendations, suspect cases underwent oro-pharyngeal swabs for virus detection using ribonucleic acid (RNA) polymerase chain reaction (PCR) ${ }^{3-5}$ Those found positive were then carefully followed-up with quantitative IgM- and IgG-based serologic tests. ${ }^{34-36}$

To define COVID-19 disease severity, we chose the NIH classification ${ }^{37}$ as the most suitable one in our clinical setting, heavily clogged with hectic health care activities.

T2DM diagnosis and comorbidities/complications related to DM relied on criteria defined by the ADA Standards of Medical Care in Diabetes $2019^{38}$ and on the International Classification of Diseases, Clinical Modification (ICD-9-CM, V82.9 2014), ${ }^{39}$ respectively.

The study was conducted following the Helsinki Declaration 1975 and subsequent amendments. The protocol was approved by the Ethics Committee of the University of Campania "Luigi Vanvitelli" on June 3, 2020 (Protocol Registration N. 1394b) as follow-up of previous paper, already approved on April 30, 2020 (protocol registration n. 1394), and published on the same Journal. ${ }^{11}$ 
It was formally approved by the Ethics Committee of the University of Campania "Luigi Vanvitelli" on April 30, and again for the present analysis as an extension of the previous approval on November 3, 2020. According to good clinical practice guidelines, the data was processed anonymously, and no patient started the study before signing informed consent. All the subjects enrolled signed the informed consent.

Results, expressed as mean $\pm \mathrm{SD}$ or $\%$, relied on the utilization of the Statistical Analysis System (SAS) Program (Release 9.4, SAS Institute, Cary, NC, USA), which also allowed to perform the chi-square test with Yates correction or Fisher Exact test for categorical variables, as well as the analysis of variance for repeated measures (rANOVA) supplemented by the two-tailed Student's $t$ test or Mann-Whitney U-test with $95 \%$ confidence intervals (CI) for parametric variables or nonparametric variables, respectively. The least acceptable significance level was set at a $p<0.05$.

\section{RESULTS}

In Italy the two periods of the pandemic were characterized by a strong association between mortality rate and often intertwined comorbidities, mostly represented by AH, Type $2 \mathrm{DM}$ (T2DM), ischemic heart disease (IHD), and chronic kidney disease (CKD) ${ }^{5,10}$ As reported in Table 2, while showed no significant period-dependent differences, data from the ISS on mortality rate and factors associated with COVID-19 pointed to co-existing comorbidities, mostly represented by the AH, T2DM and CKD triplet, as an extremely unfavorable prognostic factor.

Table 1 shows our 873 patients' general features as of November 2020 and differences among main comorbidities as referred to the presence/absence of T2DM. People with T2DM were older and had a higher BMI and comorbidity rate except for dementia, stroke, and respiratory failure $(p<0.05)$; those on insulin were $77.9 \%$. Results were almost superimposable to those we observed in April 2020.

Table 3, comparing SARS-CoV-2 contagion data from both periods, shows the strikingly different infection prevalence occurring within the HCP ( $\mathrm{n}=75$ vs. 0 ) despite strict compliance to the prevention protocol within all DCs over time. However, SARS-

CoV-2 positive HCP had only mild symptoms (NIH classification scores 1-2). ${ }^{35}$ if so ever (thus requiring no hospitalization). Based on triage and tracking investigations, they had got mostly infected outside the DCs, mainly when spending August-September holidays in places characterized by a high virus circulation rate.

\begin{tabular}{|c|c|c|c|c|}
\hline \multirow[b]{3}{*}{ Diseases } & rbidities & rved in & $\mathrm{S}-\mathrm{CoV}-2$ & Deceased \\
\hline & \multicolumn{2}{|c|}{$\begin{array}{l}\text { Data Available on } \\
\text { April } 23,2020(*)\end{array}$} & \multicolumn{2}{|c|}{$\begin{array}{c}\text { Data Available on } \\
\text { November } 13,2020\left(^{\circ}\right)\end{array}$} \\
\hline & $\mathbf{N}$ & $\%$ & $\mathbf{N}$ & $\%$ \\
\hline Ischemic Heart disease & 562 & 27.5 & 1449 & 27.7 \\
\hline Atrial Fibrillation & 450 & 22.0 & 1266 & 24.2 \\
\hline Heart Failure & 328 & 16.1 & 858 & 16.4 \\
\hline Stroke & 228 & 11.2 & 595 & 11.4 \\
\hline Hypertension & 1410 & 69.1 & 3441 & 65.7 \\
\hline Type 2 Diabetes & 647 & 31.7 & $|53|$ & 29.3 \\
\hline Dementia & 307 & 15.0 & 1148 & 21.9 \\
\hline $\begin{array}{l}\text { COPD (Chronic Obstructive } \\
\text { Pulmonary Disease) }\end{array}$ & 350 & 12.1 & 895 & 17.1 \\
\hline $\begin{array}{l}\text { Active Cancer in the past } \\
5 \text { years }\end{array}$ & 328 & 16.1 & 896 & 17.1 \\
\hline Chronic Liver Disease & 81 & 4.0 & 244 & 4.7 \\
\hline Chronic Renal Disease & 431 & 21.1 & 1099 & 21.0 \\
\hline Dialysis & 43 & 2.1 & 109 & 2.1 \\
\hline Respiratory Failure & 110 & 5.4 & 345 & 6.6 \\
\hline HIV Infection & 5 & 0.2 & 11 & 0.2 \\
\hline Autoimmune Diseases & 76 & 3.7 & 223 & 4.3 \\
\hline Obesity & 249 & 12.2 & 541 & 10.3 \\
\hline \multicolumn{5}{|l|}{ Number of Co-morbidities } \\
\hline 0 & 74 & 3.6 & 174 & 3.3 \\
\hline 1 & 294 & 14.4 & 682 & 13.0 \\
\hline 2 & 431 & 21.1 & 988 & 18.9 \\
\hline 3 & 1242 & 60.9 & 3390 & 64.8 \\
\hline Total subjects & 2041 & 100.0 & 5234 & 100.0 \\
\hline (*) Source I $2 ;\left(^{\circ}\right)$ Source IO & & & & \\
\hline
\end{tabular}

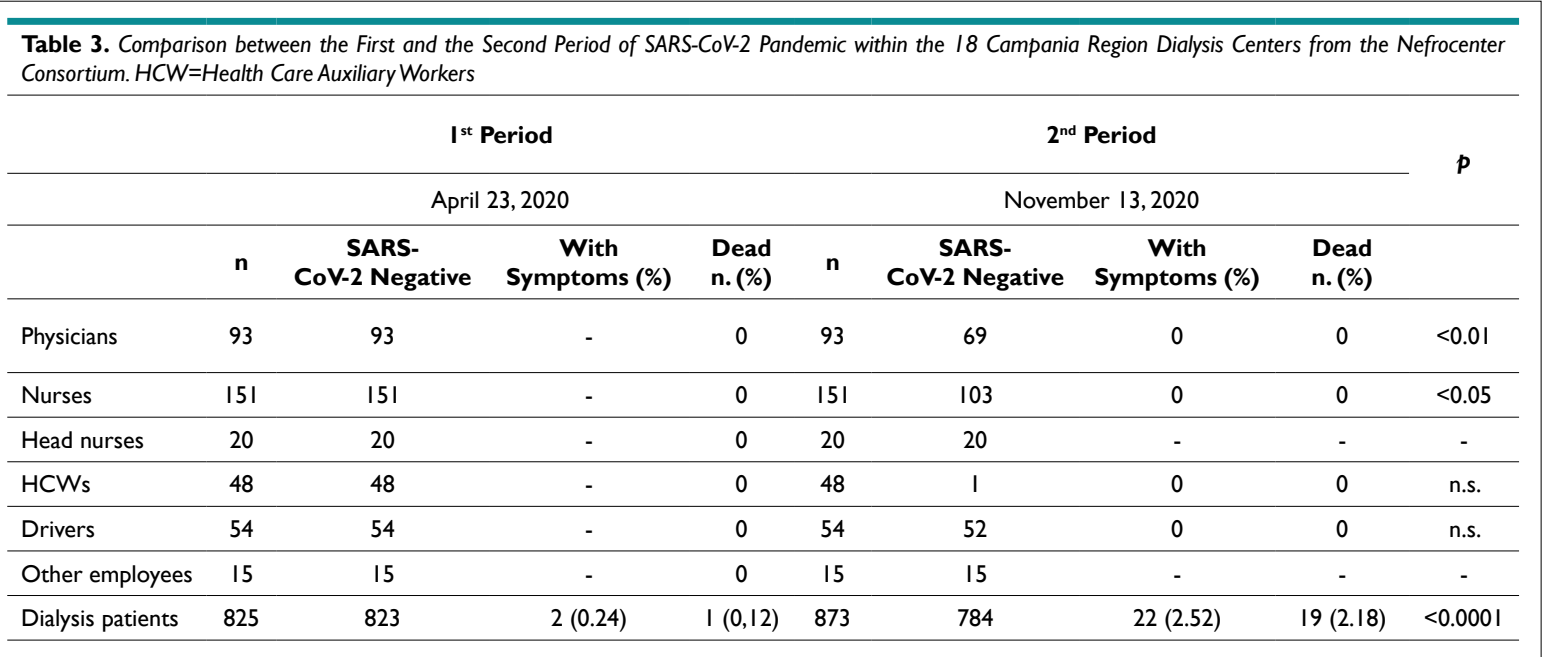




\begin{tabular}{|c|c|c|c|c|}
\hline & $\begin{array}{c}\text { SARS-CoV-2 } \\
\text { positive patients } \\
(\text { (n. 89) }\end{array}$ & $\begin{array}{c}\text { SARS-CoV-2 } \\
\text { negative patients } \\
(\mathrm{n} .784)\end{array}$ & & \multirow[t]{2}{*}{$\begin{array}{c}\text { Total } \\
n .\end{array}$} \\
\hline & $\mathbf{N} \%$ & $\mathbf{N} \%$ & $p$ & \\
\hline \multicolumn{5}{|l|}{ Comorbidities } \\
\hline $\mathrm{IHD} / \mathrm{AF} / \mathrm{HF} *$ & 1269.16 & 38649.23 & $<0.0001$ & 398 \\
\hline Stroke & 77.87 & 17622.45 & $<0.001$ & 183 \\
\hline Arterial hypertension & 7685.39 & 50964.92 & $<0.01$ & 585 \\
\hline Type 2 diabetes mellitus & 7988.76 & 25332.40 & $<^{\prime} 000$ I & 332 \\
\hline $\begin{array}{l}\text { Chronic obstructive } \\
\text { pulmonary disease }\end{array}$ & 3134.83 & 17822.70 & $<0.01$ & 209 \\
\hline $\begin{array}{l}\text { Active cancer in the } \\
\text { past } 5 \text { years }\end{array}$ & 22.25 & $0-$ & - & 2 \\
\hline Dementia & 910.11 & 273.44 & $<0.05$ & 36 \\
\hline Chronic liver disease & 1921.35 & 15619.90 & n.s. & 175 \\
\hline Respiratory failure & 1415.73 & 13417.59 & n.s. & 148 \\
\hline \multicolumn{5}{|c|}{ Number of Comorbities } \\
\hline 0 & $0-$ & 50.64 & - & 5 \\
\hline 1 & $0-$ & 10513.39 & - & 105 \\
\hline 2 & $0-$ & 18924.11 & - & 189 \\
\hline 3 at least & 89100.00 & 48561.86 & $<' 0001$ & 574 \\
\hline
\end{tabular}

More patients showed to be infected in November than in April (2 out of 825 people; 0,24\%) as well, summing up to 89 out of 873 people $(10.19 \%)$. As many as 22 patients from the November cohort required hospitalization for moderate-severe symptoms $(24.7 \%$ of the 89 SARS-CoV-2 positive subjects and $2.5 \%$ of the whole attending population), with death unavoidably coming in 19 (86.3\% of hospitalized and $21.3 \%$ of infected patients) compared to the only one recorded in April (0.12\%).

Table 4 shows differences among SARS-CoV-2 positive $(n=89)$ and negative $(n=784)$ patients as for type and number of comorbidities, compared to those from ISS reports issued before the pandemic (Table 2). No HIV infection, autoimmune disease, or obesity cases were present in our population. The prevalence of all comorbidities was significantly higher in SARS-CoV-2 positive patients except for cancer (we avoided statistics for the too few [only two] active cases reported during the past five years). Also, all SARS-CoV-2 positive patients, compared to only $61.8 \%$ of SARSCoV-2 negative ones, suffered at least three comorbidities.

\section{DISCUSSION AND CONCLUSION}

From the analysis of the two pandemic periods, quite different pictures arise. During the first wave, due to government directives and the ubiquitous fear of a virus, which was unknown even to the experts, the whole population strictly observed contagion prevention strategies. As a result, the virus spread kept at low-levels in Italy, despite significant differences between the Northern regions and the others, ${ }^{40,41}$ despite reported long-term persistence of viral particles and a potentially high infection risk within health care facilities. ${ }^{41-43}$
The lack of any contagion signs among the HCP while detecting only two infected patients in the DCs during the first period $^{11}$ seems to support both the favorable environmental condition outside DCs and the effectiveness of containment's protocol adopted inside the DCs. ${ }^{11}$ The explanation for that seemed to rely on the hypothesized large removal of the already reduced inflammatory storm-related cascade of cytokines by dialysis ${ }^{44}$ produced by the defective immune system characterizing people with CKD19 during the acute phases of SARS-CoV-2 infection. ${ }^{37}$ Of course, all the above could not nullify but only mitigate CKD patients' comorbidity-related frailty and high mortality rate reported by the ISS. ${ }^{10}$

On the opposite, SARS-CoV-2 positive HCP members and patients found during the second wave of the pandemic were quite many, yet, being infection severity negligible among the HCP, a high prevalence of cases of moderate-severe symptoms leading to hospitalization was recorded among patients. Only $13.4 \%$ of the HCP $(n=14)$ was over 50 -years of age $v$ s. $100 \%$ of patients. Only $36.0 \%$ of the infected HCP had one comorbidity (invariably $\mathrm{AH}$ ), while $100 \%$ of infected patients suffered at least three comorbidities. Apropos of that, our data support the strong association found by the ISS in the Italian population between at least three combined comorbidities and the high morbidity and mortality rate of people on dialysis. ${ }^{45-47}$

How to explain the considerable difference observed between the two periods? On displaying pandemic trend in Italy since the very beginning, Figure 1 depicts the exponential rise observed in November, and Figure 2 provides evidence of the ubiquitous 
virus spread. In other words, the positive effect of lockdown performed in spring 2020 vanished after summertime containment measure loosening. Media repeatedly and uselessly stigmatized unstoppable dangerous behaviors, including thoughtless aggregation of many people, totally disregarded social distancing and failure to wear masks despite numerous infected people identified daily all over Europe. In greater detail, during the summer discos opened again everywhere in Europe and especially in Sardinia (an almost COVID-free region until mid-August), international travel exchanges started again. Simultaneously, more and more events, including festivals, funerals, mass religious celebrations/processions, and political gatherings, involved hundreds of people, and school reopening overcrowded public transportation - thus hindering social distancing during rush hours. All phenomena mentioned above made the virus spread much faster than before, especially in the presence of many, mostly young, asymptomatic infected people who largely hindered effective tracking despite ever-updated safety protocols issued at regular intervals. ${ }^{48-51}$ To overcome this problem, the Italian government offered the IMMUNI App for smart phones associated with Bluetooth Low Energy technology for free in order to track suspected cases and identify contacts with SarsCoV-2 positive people. ${ }^{42}$ However, due to privacy concerns, only a few people felt confident enough to download and use the App, thus nullifying such a nation-wide strategy. ${ }^{52}$

All this shows how contagion containment measures adopted by our DCs were not enough to fight the global infection risk pending on the whole Italian social community around. The most evident proof of this is the fact that, opposite to what we observed during the previous period, many HCP members "imported" the SARS-CoV-2 virus from highly infected touristic places before the second wave. Since early September 2020, the Nefrocenter Consortium adopted an add-on protocol meant to identify, track and monitor suspected cases, and thus stop contagion spread within its DCs by identifying and isolating suspected cases and their contacts. It also organized COVID-dedicated DCs to keep patients on dialysis, as suggested by other experiences, ${ }^{53-57}$ while reinforcing safety procedures for the sake of health personnel, patients, and relatives.

In conclusion, we now summarize lessons learned from such stressing experience to help the scientific community take the weighty responsibility of assisting dialyzed people appropriately and safely in times of COVID-19 contagion:

1. CKD patients are frail and as susceptible to SASR-CoV-2 as anybody else;

2. The impaired immune responsivity, despite possible pro-inflammatory cytokine clearance provided by dialysis, might not prevent CKD patients from undergoing severe/lethal consequences;

3. The high comorbidity rate is an unfavorable factor increasing the risk of clinically severe infections eventually leading dialysis patients to hospitalization;

4. Patients chronically undergoing dialysis have a very high-risk of dying after hospitalization for moderate/severe infection symptoms;
5. Environmental circulation of SARS-CoV-2 virus also dramatically increases contagion rate in dialysis units independently of highly effective safety protocols complying with current recommendations from local and national health institutions;

6. However, adopting a suitable surveillance and monitoring protocol for suspected/infected subjects grants an effective contagion tracking activity, thus preventing local COVID-19 outbreaks within DCs.

\section{LIMITATIONS}

The present study suffers the main limitation of being based on a single Italian region endowed with a socio-economic reality somewhat differing from other ones characterized by equally relevant virus circulation rates, further exacerbated by highly concentrated industrial activities and massive use of means of transport.

However, its multicenter structure and the large size of its population allow for reliable, updated results. Also, it deserves credit for warning dialysis specialists about the fact that, despite proving effective for the HCP, prevention protocols could fail to protect the frailest patients with T2DM from the effects of an aggressive outer environment.

\section{ACKNOWLEDGEMENTS}

We acknowledge the logistic support of Nefrocenter Research Network \& Nyx, research startup, Naples, Italy.

\section{INFORMED CONSENT |}

Written informed consent was obtained from all participants before enrollment.

\section{FUNDING}

The study did not have a sponsor/funder. Nefrocener Research Network \& Nyx Statrup paid only the printing costs in a nonconditioning way.

\section{AUTHORSHIP |}

All named authors meet the International Committee of Medical Journal Editors (ICMJE) criteria for authorship for this article, take responsibility for the integrity of the work as a whole, and have given their approval for this version to be published.

\section{AUTHOR'S CONTRIBUTION}

SG, ES, CR and FS created the paper and wrote it. CA, TDC, MP critically read the paper. All have complied with data collection, critically assessed the results, and approved the final text. All collaborators critically read and approved the final text.

\section{STUDY INVESTIGATORS}

For full investigator list see the Appendix. 


\section{COMPLIANCE WITH ETHICS GUIDELINES}

This study was conducted in conformance with good clinical practice standards. The study was led in accordance with the Declaration of Helsinki 1975, as revised in 2013. Written informed consent was obtained from all participants before enrollment.

The protocol was approved by the Ethics Committee of the University of Campania "Luigi Vanvitelli" on June 3, 2020 (protocol registration n. 1394-b) as follow-up of previous paper, already published on the same Jornal "COVID-19, DLABETES AND DIALYSIS: AN INTERNAL MEDICINE CONUNDRUM: Proposal for a suitable and easy-to-handle prevention protocol' (reference 11).

\section{DATA AVAILABILITY}

The datasets analyzed during the current study are available from the corresponding author on reasonable request.

\section{CONFLICTS OF INTEREST}

The authors declare that they have no conflicts of interest.

\section{REFERENCES}

1. World Health Organization (WHO). Virtual press conference on COVID-19_11 March 2020. March 11, 2020. Web site. https://www.who.int/docs/default-source/coronaviruse/transcripts/who-audioemergencies-coronavirus-press-conferencefulland-final-11 mar2020.pdf?sfvrsn $=$ cb432bb3_2. Accessed November 15, 2020.

2. Bedford J, Enria D, Giesecke J, Heymann DL, Ihekweazu C, Kobinger G, et al. COVID-19: Towards controlling of a pandemic. Lancet. 2020; 395(10229): 1015-1018. doi: 10.1016/S01406736(20)30673-5

3. Government of Italy. Decree of the president of the Council of Ministers 9 March 2020. March 9, 2020 [n: Italian]. Web site. https://www.gazzettaufficiale.it/eli/id/2020/03/09/20A01558/ sg. Accessed November 15, 2020.

4. Government of Italy. Decree of the president of the Council of Ministers 11 March 2020. March 11, 2020. Web site. https:// www.gazzettaufficiale.it/eli/id/2020/03/11/20A01605/sg [In: Italian]. Accessed November 15, 2020.

5. Gentile S, Strollo F, Ceriello A. COVID-19 infection in Italian people with diabetes: Lessons learned for our future (an experience to be used). Diabetes Res Clin Pract. 2020; 162: 108137. doi: 10.1016/j.diabres.2020.108137

6. Setti L, Passarini F, De Gennaro G, Barbieri P, Perrone MG, Borelli M, et al. Airborne transmission route of COVID-19: Why 2 Meters/ 6 Feet of inter-personal distance could not be enough.
Int J Environ Res Public Health. 2020; 17(8): 2932. doi: 10.3390/ ijerph17082932

7. Fattorini D, Regoli F. Role of the chronic air pollution levels in the Covid-19 outbreak risk in Italy. Environ Pollut. 2020; 264: 114732. doi: 10.1016/j.envpol.2020.114732

8. Gentile S, Mambro A, Strollo F. Parallel epidemics, or nearly so: Certainties and uncertainties about SARS-CoV-2 in Italy. Diabetes Res Clin Pract. 2020; 164: 108195. doi: 10.1016/j.diabres.2020.108195

9. Romagnani P, Gnone G, Guzzi F, Negrini S, Guastalla A, Annunziato $\mathrm{F}$, et al. The COVID-19 infection: lessons from the Italian experience. J Public Health Policy. 2020; 41(3): 238-244. doi: 10.1057/s41271-020-00229-y

10. IstitutoSuperiore di Sanità. Characteristics of SARS-CoV-2 patients dying in Italy: Report based on available data. Web site. https://www.epicentro.iss.it/en/coronavirus/bollettino/ReportCOVID-2019_11_november_2020.pdf. Accessed November 11, 2020.

11. Strollo F, Satta E, Romano C, Alfarone C, Corte TD, Guarino $\mathrm{G}$, et al. Coronavirus disease-2019, diabetes and dialysis: an internal medicine conundrum proposal for a suitable and easy-tohandle prevention protocol. Diabetes Res Open J. 2020; 6(2): 27-36. doi: 10.17140/DROJ-6-147

12. ISS Report, april 23, 2020. Characteristics of SARS-CoV-2 patients dying in Italy Report based on available data on April 23th, 2020. IstitutoSuperiore di Sanità. Web site. https://www.epicentro. iss.it/en/coronavirus/bollettino/Report-COVID-2019_23_ april_2020.pdf. Accessed October 22, 2020.

13. de Boer IH, Rue TC, Hall YN, Heagerty PJ, Weiss NS, Himmelfarb J. Temporal trends in the prevalence of diabetic kidney disease in the United States. JAMA. 2011; 305(24): 2532-2539. doi: 10.1001/jama.2011.861

14. Collins AJ, Foley RN, Chavers B, Gilbertson D, Herzog C, Ishani A, et al. US Renal data system 2013 annual data report. $A m \mathrm{~J}$ Kidney Dis. 2014; 63(1 Suppl): A7. doi: 10.1053/j.ajkd.2013.11.001

15. Tuttle KR, Bakris GL, Bilous RW, Chiang JL, de Boer IH, Ji Goldstein-Fuchs J, et al. Diabetic kidney disease: A report From an ADA consensus conference. Diabetes Care. 2014; 37(10): 28642883. doi: $10.2337 / \mathrm{dc} 14-1296$

16. D'Aria I. Intervista a Fabio Malberti all'Ospedale di Cremona del 21 aprile 2020. Coronavirus, i pazienti in dialisi rischiano di più. La Repubblica [n: Italian]. Web site. https://www. repubblica.it/salute/medicina-e-ricerca/2020/04/21/news/ coronavirus_i_pazienti_in_dialisi_rischiano_di_piu_ma_con_la_ cura_a_domicilio_meno_covid-positivi-254523027/. Accessed October 22, 2020. 
17. Italian Society of Nephrology (SIN). Protocollo CORONAVIRUS \& DIALISI. Web site. https://sinitaly.org/wp-content/ uploads/2020/02/Coronavirus-Dialisi.pdf. Accessed October 22,2020 .

18. Ministero della Salute. Covid-19-Raccomandazioni per gli operatori sanitari. Web site. http://www.salute.gov.it/portale/ nuovocoronavirus/dettaglioContenutiNuovoCoronavirus.jsp?lin gua $=$ italiano $\& i d=5373 \&$ area $=$ nuovoCoronavirus $\&$ menu $=$ vuoto. Accessed October 22, 2020.

19. Ma Y, Diao B, Lv X, Zhu J, Liang W, Liu L, et al. 2019 novel coronavirus disease in hemodialysis (HD) patients: Report from one HD center in Wuhan, China. Med Rxiv. 2020; doi: 10.1101/2020.02.24.20027201

20. Naicker S, Yang C-W, Hwang S-J, Liu B-C, Chen J-H, Jha $\mathrm{V}$. The novel coronavirus 2019 epidemic and kidneys. Kidney Int. 2020; 97(5): 824-828. doi: 10.1016/j.kint.2020.03.001

21. Epidemiology Working Group for NCIP Epidemic Response, Chinese Center for Disease Control and Prevention. The epidemiological characteristics of an outbreak of 2019 novel coronavirus disease (COVID-19) - China. 2020. Zhonghua Liu Xing Bing Xue Za Zhi. 2020; 41(2): 145-151. doi: 10.3760/cma.j.is sn.0254-6450.2020.02.003

22. Zhou J, Li C, Zhao G, Chu H, Wang D, Hoi-Ning Yan H, et al.Human intestinal tract serves as an alternative infection route forMiddle East respiratory syndrome coronavirus. Sci Adv. 2017; 3(11): eaao4966. doi: 10.1126/sciadv.aao4966

23. Daichou Y, Kurashige S, Hashimoto S, Suzuki S. Characteristic cytokine products of Th1 and Th2 cells in hemodialysis patients. Nephron. 1999; 83(3): 237-245. doi: 10.1159/000045516

24. Wang R, Liao C, He H, Hu C, Wei Z, Hong Z, et al. COVID-19 in hemodialysis patients: A report of 5 cases. Am J Kidney Dis. 2020; 76(1): 141-143. doi: 10.1053/j.ajkd.2020.03.009

25. Tang B, Li S, Xiong Y, Tian M, Yu J, Xu L, et al. Coronavirus disease 2019 (COVID-19) pneumonia in a hemodialysis patient. Kidney Med. 2020; 2(3): 354-358. doi: 10.1016/j.xkme.2020.03.001

26. Perico L, Benigni A, Remuzzi G. Should Covid-19 concern nephrologist? Why and to what extent? The emerging impasse of angiotensin blockade. Nephron. 2020; 144(5): 213-221. doi: $10.1159 / 000507305$

27. Razzini K, Castrica M, Menchetti L, Maggid L, Negronia L, Orfeo NV, et al. SARS-CoV-2 RNA detection in the air and on surfaces in the COVID-19 ward of a hospital in Milan, Italy. Sci Total Environ. 2020; 742: 140540. doi: 10.1016/j.scitotenv.2020.140540

28. Felice C, Di Tanna GL, Zanus G, Grossi U. Impact of COVID-19 Outbreak on Healthcare Workers in Italy: Results from a
National E-Survey. J Community Health. 2020; 45(4): 675-683. doi: 10.1007/s10900-020-00845-5

29. Italian Society of Nephrology (SIN). Protocol CORONAVIRUS \& DIALISI. Web site. https://sinitaly.org/wp-content/ uploads/2020/02/Coronavirus-Dialisi.pdf. Accessed October 22, 2020.

30. Ministero della Salute. Covid-19-Raccomandazioni per gli operatori sanitari. Web site. http://www.salute.gov.it/portale/ nuovocoronavirus/dettaglioContenutiNuovoCoronavirus.jsp?lig ua $=$ italiano\&id $=5373 \&$ area $=$ nuovoCoronavirus $\&$ menu $=$ vuoto. Accessed October 22, 2020.

31. Kliger AS, Silberzweig J. Mitigating risk of COVID-19 in dialysis facilities. Clin J Am Soc Nephrol. 2020; 15(5): 707-709. doi: 10.2215/CJN.03340320

32. Ordinanza del Capo della Protezione Civile n. 640 del 27 febbraio 2020. Web site. http://www.protezionecivile.gov.it/ amministrazione-trasparente/provvedimenti/dettaglio/-/asset_publisher/default/content/ocdpc-n-640-del-27-febbraio2020-ulteriori-interventi-urgenti-di-protezione-civile-in-relazione-all-emergenza-relativa-al-rischio-sanitario-connesso-a. Accessed October 22, 2020.

33. Le indicazioni dei CDC. Interim Guidelines for Collecting, Handling, and Testing Clinical Specimens for COVID-19 (aggiornamento al 5 maggio 2020). Web site. https://www.epicentro.iss. it/coronavirus/sars-cov-2-sorveglianza. Accessed October 22, 2020 .

34. World Health Organization (WHO). WHO Interim guidance Laboratory testing for coronavirus disease (COVID-19) in suspected human cases (Aggiornamento al 19 marzo 2020). https://www.who.int/emergencies/diseases/novel-coronavirus-2019?gclid=Cj0KCQiAh4j-BRCsARIsAGeV12CovORp8MKFxvNXn03kwYFFvHCDOLZvJEME39I7TKOSDQnoQax4eaQaAmI4EALw_wcB. Accessed October 22, 2020.

35. Ministero della Salute, ISS, WHO document 2020. Prevenzione e risposta a COVID-19: evoluzione della strategia e pianificazione nella fase di transizione per il periodo autunno-invernale Approfondimento complementare ai documenti generali già resi pubblici su preparedness, pianificazione e contesti specifici. Misure aggiuntive di contenimento del contagio e gestione dei casi SARS-CoV-2 positivi. [In: Italian]. Web site. http://www.salute. gov.it/imgs/C_17_pagineAree_5373_16_file.pdf. Accessed October 22, 2020 .

36. World Health Organization (WHO). Clinical management of COVID-19; Interim guidance 27 May 2020. Geneva: WHO; 2020. Web site. https://apps.who.int/iris/bitstream/ handle/10665/332196/WHO-2019-nCoV-clinical-2020.5- eng. pdf? sequence $=1$ \&isAllowed $=\mathrm{y}$. Accessed October 22, 2020.

37. National Institutes of Health. COVID-19 Treatment Guide- 
lines. Management of persons with COVID-19. Bethesda, MD $\mathrm{NIH}$; 2020. Web site. https://files.covid19treatmentguidelines. nih.gov/guidelines/covid19treatmentguidelines.pdf. Accessed October 22, 2020.

38. ADA Classification and diagnosis of diabetes. Standards of medical care in diabetes-2019. Diabetes Care. 2019; 42(Suppl 1): S13-S28. doi: 10.2337/dc19-Sint01

39. International Classification of Diseases, Ninth Revision, Clinical Modification (ICD-9-CM). National Center for Health Statistics. Web site. https://www. cdc.gov/nchs/icd/icd9cm.htm. Accessed January 7, 2020.

40. Gentile S, Mambro A, Strollo F. Parallel epidemics, or nearly so: Certainties and uncertainties about SARS-CoV-2 in Italy. Diabetes Res Clin Pract. 2020; 164: 108195. doi: 10.1016/j.diabres.2020.108195

41. Yuan J, Li M, Lv G, Lu ZK. Monitoring transmissibility and mortality of COVID-19 in Europe. Int J Infect Dis. 2020; 95: $311-$ 315. doi: 10.1016/j.ijid.2020.03.050

42. Presidenza del Consiglio dei Ministri. App Immuni. Web site. http://www.governo.it/it/approfondimento/immuni/15336. Accessed October 22, 2020.

43. Sky-Th-24. App Immuni, ecco perché il sistema di tracciamento non ha funzionato. Web site. https://tg24.sky.it/tecnologia/2020/10/23/app-immuni-non-funziona. Accessed October 20, 2020.

44. Huang L, Wang Y, Wang L, Lv Y, Liu Q. Coronavirus disease 2019 (COVID-19) pneumonia in a hemodialysis patient: A case report. Medicine (Baltimore). 2020; 99(27): e20956. doi: 10.1097/ MD.0000000000020956

45. Rombolà G, Hedemperger M, Pedrini L, Farina M, Aucella F, Messa P, et al. Practical indications for the prevention and management of SARS-CoV-2 in ambulatory dialysis patients: Lessons from the first phase of the epidemics in Lombardy. $J$ Nephrol. 2020; 33(2): 193-196. doi: 10.1007/s40620-020-00727-y2020

46. Ikizler TA. COVID-19 and dialysis units: What do we know now and what should we do? Am J Kidney Dis. 2020; 76(1): 1-3. doi: $10.1053 /$ j.ajkd.2020.03.008

47. Chen G, Zhou Y, Zhang L, Wang Y, Hu R-R, Zhao X, et al. Core principles for infection prevention in hemodialysis centers during the COVID-19 pandemic. Infect Control Hosp Epidemiol. 2020; 41(7): 865-866. doi: 10.1017/ice.2020.109

48. La Stampa newspaper. Covid, discoteche aperte in Sardegna: aperta un'inchiesta per epidemia colposa. [In: Italian]. Web site. https://www.lastampa.it/cronaca/2020/11/10/news/coviddiscoteche-aperte-in-sardegna-aperta-un-inchiesta-per-epidemiacolposa-1.39523163. Accessed Novembre 10, 2020.

49. Comune di Budoni. Coronavirus: ORDINANZA N. 31 DEL 4 LUGLIO 2020 - Processioni religiose e manifestazioni tradizionali. Web site. http://www.comunebudoni.gov.it/index. php?id=76\&oggetto=112. Accessed Novembre 10, 2020.

50. Coronavirus, stop a matrimoni e funerali: le regole in chiesa dalla messa in tv alla confessione a distanza. 9 marzo 2020. Web site. https://www.ilsole24ore.com/art/coronavirus-stop-matrimoni-e-funerali-regole-chiesa-messa-tv-confessione-distanzaADCPyxB?refresh_ce=. Accessed Novembre 10, 2020.

51. Unità di Crisi Regionale della Campania. ex Decreto P.G.R.C. n. 51 del 20/3/2020. PROTOCOLLO DI SICUREZZA ANTIDIFFUSIONE SARS-COV-2 WEDDING E CERIMONIE. Web site. https://thewam.net/wp-content/uploads/2020/09/ all-3-ord-75-protocollo-wedding-cerimonie.pdf. Accessed Novembre 10, 2020.

52. Sky-Th-24. App Immuni, ecco perché il sistema di tracciamento non ha funzionato. Web site. https://tg24.sky.it/tecnologia/2020/10/23/app-immuni-non-funziona. Accessed October 20, 2020.

53. Meijers B, Messa P, Ronco C. Safeguarding the maintenance hemodialysis patient population during the Coronavirus disease 19 pandemic. Blood Purif. 2020; 49(3): 1-6. doi: 10.1159/000507537

54. de Sequera Ortiz P, Quiroga Gili B, del a Fuente GA, Macía Heras M, Salgueira Lazo M, del Pino y Pino MD, et al. Protocolo de actuación ante la epidemia de enfermedad porc oronavirus enlos pacientes de diálisisy trasplantados renales. [In: Spanish]. Nefrologia. 2020; 40(3): 253-257. doi: 10.1016/j.nefro.2020.03.001

55. Wang H. Maintenance hemodialysis and coronavirus disease 2019 (COVID-19): Saving lives with caution, care, and courage. Kidney Med. 2020; 2: 365-366. doi: 10.1016/j.xkme.2020.03.003 33

56. Meijers B, Messa P, Ronco C. Safeguarding the maintenance hemodialysis patient population during the coronavirus disease 19 pandemic. Blood Purif. 2020; 49(3): 259-264. doi: $10.1159 / 000507537$

57. BC Renal. HD Infection Control: COVID-19 (WORKING COPY Mar 17, 2020). Guideline: Novel coronavirus (COVID-19) for Hemodialysis Outpatients. Web site. http://www.bcrenalagency. ca/resource-gallery/Documents/COVID-19_Guideline_ for_Hemodialysis_Programs.pdf. Accessed October 22, 2020. 


\section{Members of Nefrocenter Research Study Group}

Nephrologists: Meccariello Sergio, Cicala Michele, Crisci Fabrizio, Leone Ferdinando, Marino Raffaele, Romano Massimo, Cristiano Giuseppina, Riccio Eleonora, D’Anna Francesco, Borghesi Francesca, Di Gennaro Luigi, Raiola Ilaria, La Manna Anna Maria, Cicala Michele, Boccia Pasquale, Garofalo Gianluca, Castellano Tiziana, Fimiani Vanessa, Girone Aniello, Angelino Adele, Di Livio Rosalba, Celentano Sonia, Petruzzelli Luigi Annichiarico, Cuomo Anna, Latte Gianluca, Oliviero Simona, Capuano Ivana, Scarpati Lisa, Lubrano Giuseppe, Giordano Laura, Sorrentino Rachele, Di Monte Mauro, Savino Francesco Antonio, Abategiovanni Maria Luisa, Vendemia Pasquale, Garofalo A, Caiazza Antonella, Scarfato Anna, Visone Antonio, Porpora Danilo, Mazzarella Renato, Botta Carmine, Di Gruttola Oto, Sorrentino Livia, Kseniya, Vitale Sossio, Cupic Iris, Di Stazio Vincenzo, Satta Ersilia, Monte Giovanni, Barbuto Gennaro, D’Errico Francesco, Ciccarelli Antonio, Verrillo Edoardo, Nappo Maria, De Maio Alfonso, Miano Pietro, Trapanese Ersilio, Brengola Giovanni, Reggio Rosario, Pagano Teresa, Crispino Nicola, Napolitano Poala, Roberta, Cipriano Secondino, Mercogliano Fulvio, Salemi Fabrizio, Alfarone Carmelo, Romano Giuseppe, Di Leva Luigi, Barretta Raffaella.

Diabetologists: Gentile S, Guarino G, Strollo F.

Nurses: Morgillo Vincenzo, Morgillo Vincenza, Fusco Michela, Cimmarosa Angelo, Brida Michela, Guerra Anna, Spallieri Pellegrino, Cioffi Pasqualina, Massaro Giovanna, Romano Carmine, Apuzzo Rosa, Cherillo Annunziata, Erbaggio Gioacchino, Indaco Grazia, Manzo Lucia, Menna Emilio, Izzo Antonietta, Di Matola Assunta, Fontanella Filomena, Puce Milena, Fierro Gerardina, Russo Eva, Pascarella Andrea, Di Nardo Assunta, Bartiromo Alfonso, Pazdior Teresa Jadwiga, Palmiero Angela, Ruotolo Enza, Amoroso Rosa Vitale, Belardo Orfeo, Como Pasquale, Natale Maria Teresa, Erpete Luca, Occhio Aldo, Tignola Pietro Paolo, Capasso Margherita, Barbaro Fabrizio, Erpete Luca, Milano Sara, Strazzulli Michele, D’Errico Angela, Toscano Maria Emanuela, Cirillo Carmelina, Tabacco Claudia, Stasio Annunziata, Palmeri Daniela, De Vita Maria Andrea, Auletta Angela, Cozzolino Giuseppina, Migliaccio Mina, Iannone Achille, Silvestri Immacolata, Bianco Valentina, Barrella Gilda, Conturso Tiziana, Cesarini Tiziana, Ferraro Oriana, Festinese Marco, Bellocchio Luca, Pettinati Valentina, Felaco Giovanna, Ebraico Eliana, De Lucia Margarita, Mandato Ana Maria, Di Maio Giovanna, Cicchella Michelina, Cicchella Enrico, Casoria Giuseppe, Ricuperati Amelia, Calabrese Giuseppe, Isola Felice Marco, Cesarano Maria Assunta, Di Riso Marialucia, Mlynarska Malgorzata joanna, Ambrosino Lucio, Buska Halina, Esposito Gennaro, Esposito Virginia, Pandolfo Antonietta, D’Esculapio Veronica, De Costanzo Antonio, Caso Sara, Kropacheva, Casaburo Angela, Pellino Annmaria, Rainone Angela, Gigante Carmela, Imbembo Lucia, Carrara Teresa, Alibertini Paolino, Bottiglieri Lucia, D'Elia Carmine, Montesarchio Carmela, Jeschke Beata, Matusz Zuzanna, Orropesa Livio, Vitale Mario, Roselli Maria, Buonocore Giuseppina, Siani Marilina, Giove Carmelina, Petrone Elena, Russo Francesco, Salsano Antonietta, Agrisani Marilena, Giordano Domenico, Crispino Adele, De Felice Salvatore, Garofalo Gianluca, Doriano Davide, Di Virgilio Elisabetta, Fiorenza Giovanni, Mattiello Ilaria, Gala Luigi, Erricchiello Roberta, De Micco Lucia, Fioretti Ida, Gladka Ruslava, Mannato Donatella, Esposito Tommasina, Schettino Andrea, Riccio Raffaele, Allocca Anna, Rusciano Giorgio, Imbimbo Concetta, Ummarino Gabriele, Fiorenza Giovanni, Salzano Giusy, De Vincentis Emanuele, Mattiello Ilaria, Ferrante Pasquale, Passa Valentina, Siani Annalisa, Pastore Assunta, Battipaglia Maria, Martone Genoveffa, Della Monica Eligio, Bernardinelli Giuseppe, Battipaglia Daniela. 